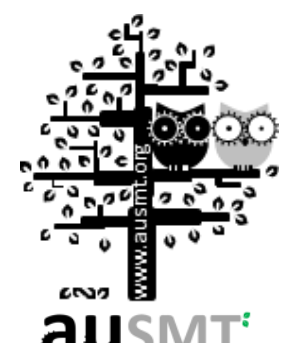

\title{
Microdroplet Protein Sensors on a Gold Surface with a Self-assembled Monolayer Treatment
}

\author{
Tzu-Chun Liao ${ }^{1}$ and J. Andrew Yeh${ }^{1,2, *}$ \\ ${ }^{1}$ Department of Power Mechanical Engineering, National Tsing Hua University, Taiwan \\ ${ }^{2}$ Institute of Nanoengineering and MicroSystems, National Tsing Hua University, Taiwan \\ (Received 31 October 2011; Accepted 9 January 2012; Published on line 1 March 2012) \\ *Corresponding author: jayeh@mx.nthu.edu.tw \\ DOI: $10.5875 / a u s m t . v 2 i 1.116$
}

\begin{abstract}
A new kind of microdroplet-based biological protein sensor is presented. The sensor was made by placing silicon oil on gold film with a self-assembled monolayer (SAM). The surface tension dominates the sensitivity of the sensor. Using mercaptoundecanoic acid (11-MUA) as the sensor's SAM layer, the sensor can detect $0.5 \mathrm{mg} / \mathrm{ml}, 20$ $\mu \mathrm{g} / \mathrm{ml}$, and $0.4 \mu \mathrm{g} / \mathrm{ml}$ bovine serum albumin (BSA) protein solutions in a control volume of $0.5 \mathrm{ml}$. The sensor's reaction time for concentrations of $0.5 \mathrm{mg} / \mathrm{ml}, 20 \mu \mathrm{g} / \mathrm{ml}$, and $0.4 \mu \mathrm{g} / \mathrm{ml}$ protein solutions was 15,60 and $120 \mathrm{minutes}$, respectively. As the size of microdroplet decreased, the change of contact angle increased.
\end{abstract}

Keywords: microdroplet; protein sensor; self-assembled monolayer (SAM)

\section{Introduction}

A biosensor is a bio-analytical device that can detect biological material and microorganisms. It can also monitor exogenous or endogenous in-vivo chemical reactions, and display the variations in sensors via a built-in transducer. These signals can then be provided to researchers for analysis $[1,2]$. In recent years, advances in biotechnology have found broad applications, including food and drug safety tests, clinical trials of new drugs and disease detection. Proteins are usually key factors in these processes, and protein sensors are a type of biosensor used in a broad range of examinations. Analysis of the protein assays is an important field of study. Applications of protein-ligand recognition reveals harmful substances in foods and can detect the presence of infection by testing potential combinations of antigens and antibodies.

The physical properties of the sensor's surface will change due to the formation of an antibody-antigen complex. These changes can easily be detected and then converted into an electrical signal via acoustical (e.g. quartz crystal microbalances (QCM) device [3-5]), optical (e.g. surface plasmon resonance (SPR) detector [6-9]), or mechanical (e.g. microcantilever beams [10, 11]) transducers. Biosensors are categorized by their transducer type (e.g., electrochemical, optical, acoustical, thermometric, mechanical, etc.). Despite their relatively high expense, optical biosensors have become more popular due to their high efficiency and sensitivity. Optical biosensor formats involve direct detection of analytes, or indirect detection through optically-labeled probes. Optical transducers can detect changes in absorbance, luminescence, polarization or refractive index.

Biomedical science has developed quickly in recent years, spawning the development of myriad related technologies. Previous methods have tended to be subject to certain disadvantages in protein-ligand recognition: a broader sample base is required, the use of immunofluorescent assays can be harmful to test subjects, and reaction times take anywhere from a few days to several weeks. 
In this study, silicon oil droplets with diameters measured in tens of micrometers are used to detect proteins, and gold film is used as a substrate for detecting changes in the protein's contact angle. The system with oil droplet in liquid was reported to adjust the droplet profile by voltages for optical focus tuning. [12-15] This recent-developed technique is simple to use, does not require highly-precise measurement equipment, and only requires $0.5 \mathrm{ml}$ of protein liquid for testing.

\section{Materials and Methods}

Materials

A gold thin film was used as the substrate to ensure biocompatibility, A 4-inch square glass substrate was coated with a $100 \mathrm{~nm}$-thick gold thin film by the E-gun system (ULVAC) to ensure biocompatibility. The glass was then cut into squares measuring $1 \mathrm{~mm}$ on a side.

The Self-Assembled-Monolayer (SAM) is a key component of a protein sensor, and the choice of SAM depends on the material used as the substrate. This study adopted mercaptoundecanoic acid (11-MUA) as a SAM. The molecule contains a twelve-carbon alkyl chain, and its functional group is carboxyl $(-\mathrm{COOH})$ which attaches with the Amino $\left(-\mathrm{NH}_{2}+\right)$ in the protein. Its head group for linking with the gold film is thiol $(-\mathrm{SH})$, and the molecular formula of the SAM is $\mathrm{HS}\left(\mathrm{CH}_{2}\right)_{10} \mathrm{COOH}$.

Bovine serum albumin (BSA) was used in three concentrations for testing. The microdroplet liquid was

Tzu-Chun Liao received his B.S. degree from Department of Mechanical Engineering, National Central University, Taoyuan, Taiwan. He got a M.S. degree from Department of Power Mechanical Engineering, National Tsing Hua University, Hsinchu, Taiwan. In his Master thesis, the protein sensor was developed by using surface plasmon resonance. He is currently a Ph.D. student at Department of Power Mechanical Engineering at National Tsing Hua University, Hsinchu, Taiwan. His current research focus is on protein sensor and cell behavior on silicon substrate.

J. Andrew Yeh is a professor co-appointed by Institute of NanoEngineering and Microsystems (iNEMS), Department of Power Mechanical Engineering (PME), and Institute of Electronics Engineering at National Tsing Hua University in Taiwan where his interests focus on dielectric liquid lenses, InN-based ambient sensors and wafer-level nanostructures for bio/opto applications. Dr. Yeh was appointed as the director of iNEMS in 2009. He serves as an editorial board member of IEEE/ASME Journal of MicroElectroMechanical Systems (JMEMS) since 2010 and as the general secretary of Taiwan Section at American Society of Mechanical Engineers (ASME Taiwan) since 2006. He has chaired the electronic platform of National K-12 Nanotechnology Education Development Center since 2008. He hosted the IEEE Optical MEMS and Nanophotonics conference 2007, NAMIS Workshop 2010, and IEEE INSS Symposium 2011. In 2001, he joined National Tsing Hua University as an assistant professor. He co-founded AIP Networks, Inc. in USA. In 1999, he was a post-doctoral associate at Cornell University in USA. He received a B.S. degree in Mechanical Engineering from National Taiwan University, Taiwan, in 1992, and Master degrees in Mechanical Engineering and in Electrical Engineering from Cornell University in 1996 and 1997, respectively. He received a Ph.D. degree in Electrical Engineering from Cornell University in 1999. silicon oil No. 704 (Dow Corning). To maintain a constant $\mathrm{pH}$ value, we used a protein liquid buffer of phosphate buffered saline (PBS), which contains sodium chloride, sodium phosphate, and (in some formulations) potassium chloride and potassium phosphate.

The monolayer deposition process had been successfully used for a number of long chain molecules on metal surfaces, and offers a simple method for surface modification at the single monolayer level [16-18].

One of the most successful techniques employed for adsorption on metal surfaces is the attachment of thiol molecules (-SH) on gold surfaces. Many self-assembly systems have been investigated, but a monolayer of alkylthiols on gold film is the most widely studied. Most of the thiol compounds investigated to date contain a long alkyl chain, which enables the compounds to form a compact monolayer on Au surfaces. However, for protein binding, the $-\mathrm{COOH}$ group can react with the $-\mathrm{NH}_{2}+$ in most protein structures. The combination of protein and SAM molecules is a covalent bond, and is thus good for signal capture.

\section{Surface treatment}

We used $250 \mathrm{ml}$ 99.5\% ethanol solution as the solvent and added $50 \mathrm{mg}$ 11-MUA powder to make $1 \mathrm{mM}$ 11-MUA solution. The gold film was washed following standard procedures: washing separately in Acetone, IPA, and $\mathrm{DI}$ water, followed by cleaning with $90^{\circ} \mathrm{C}$ vitriol solution $\left(\mathrm{H}_{2} \mathrm{O}_{2}: \mathrm{H}_{2} \mathrm{SO}_{4}=3: 7\right)$ for ten minutes. The gold film was immersed in the $1 \mathrm{mM}$ 11-MUA solution for twenty-four hours. We then used $95 \%$ ethanol to wash away the SAM molecule physical adhesion on surface of the gold film, followed by 5 min washing in an ultrasonic cleaner before pouring off the solution. We repeated this procedure three times to ensure the removal of the physical adhesive 11-MUA from the gold film. Following this procedure, the SAM film was coated on the gold film.

\section{Droplet forming}

A precisely-controlled dispenser (MUSASHI, SUPER $\Sigma x \mathrm{~V} 2$ ) was used to generate microdroplets of $20 \mu \mathrm{m}$ to $80 \mu \mathrm{m}$ in diameter by controlling the air pressure to form the volume of silicon oil required on the gold film. The test fragments were placed in a $2 \mathrm{~cm} \times 1 \mathrm{~cm} \times 0.5 \mathrm{~cm}$ acrylic receptacle boxes, submerged in $0.5 \mathrm{ml}$ PBS solution for testing. At the start of the experiment, the protein solution was added to the box and the contact angle was measured (Figure 1). 


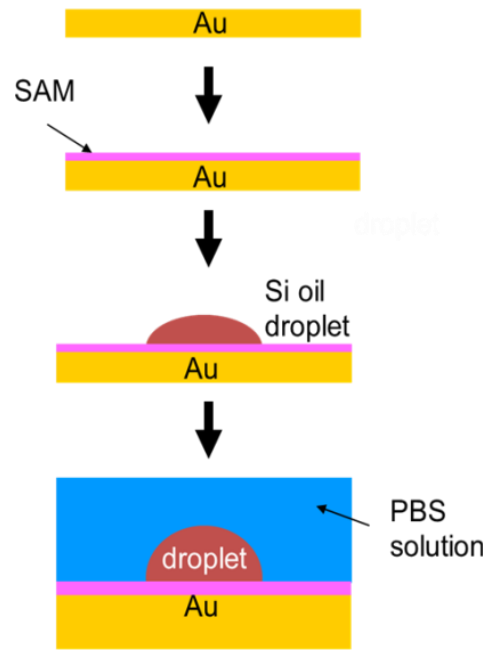

Figure 1. Sensor fabriction process.

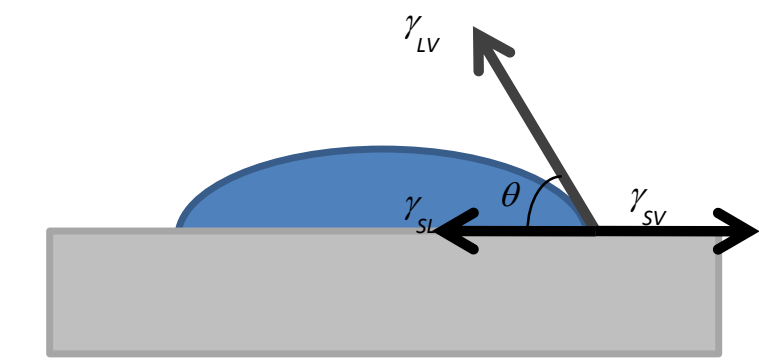

Figure 2. Three phase contact angle.

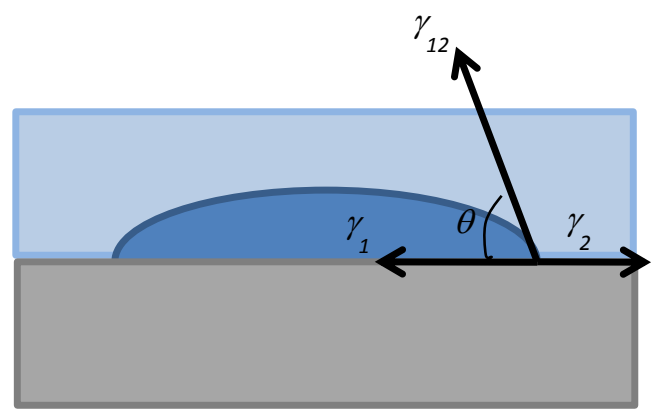

Figure 3. Contact angle in two liquids.

\section{Theory}

Young formulated the relationship between the interfacial tensions at a point in a 3-phase contact angle line (Figure 2) as follows [19]:

$$
\cos (\theta)=\frac{\gamma_{S V}-\gamma_{S L}}{\gamma_{L V}}
$$

When liquid 1 immersed in liquid 2, the equation can be rewritten as (Figure 3 ):

$$
\cos (\theta)=\frac{\gamma_{1}-\gamma_{2}}{\gamma_{12}}
$$

where

$$
\gamma_{12} \approx \gamma_{1}+\gamma_{2}-2 \times \sqrt{\gamma_{1} \gamma_{2}}
$$

where $\gamma$ is surface tension which depends on the properties of materials.

$$
\gamma=\left(\frac{\# \text { of molecules }}{\text { area }}\right)\left(\frac{\text { binding energy }}{\text { molecules }}\right)
$$

Since $\gamma$ is related to the surface tension, this property is investigated here. More rigorously, Young's equation (Equation (1)) can be rewritten as $[20,21]$

$$
\cos (\theta)=\frac{\gamma_{S V}-\gamma_{S L}}{\gamma_{L V}}-\frac{\sigma}{\gamma_{L V} R}
$$

where $\sigma$ is line tension, and $R$ is the radius of the three-phase contact circle on the plane of the solid surface. The line tension is defined as the free energy per unit length of the three-phrase contact line.

When liquid 1 immersed in liquid 2, the equation can be modified as

$$
\cos (\theta)=\frac{\gamma_{1}-\gamma_{2}}{\gamma_{12}}-\frac{\sigma}{\gamma_{12} R}
$$

The contact angle changes as the protein is bounded on the gold surface, and measuring the change in the contact angle enables protein sensing in the solution.

\section{Observation system}

A microscope with a $60 x$ objective was used to observe images captured by a CCD at a resolution of 1280 to 1024.

Concentrations of bovine serum albumin (BSA) for sensing, $0.5 \mathrm{mg} / \mathrm{ml}, 10 \mu \mathrm{g} / \mathrm{ml}$ and $0.4 \mu \mathrm{g} / \mathrm{ml}$, were tested on each of the $20 \mu \mathrm{m}, 40 \mu \mathrm{m}$, and $80 \mu \mathrm{m}$ diameter droplets.

Once the sample had been prepared in the acrylic receptacle, the protein solution was added to the PBS solution to result in respective concentrations of 0.5 $\mathrm{mg} / \mathrm{ml}, 20 \mu \mathrm{g} / \mathrm{ml}$ and $0.4 \mu \mathrm{g} / \mathrm{ml}$ per $0.5 \mathrm{ml}$ control volume. We then measured each change of contact angle several times. 


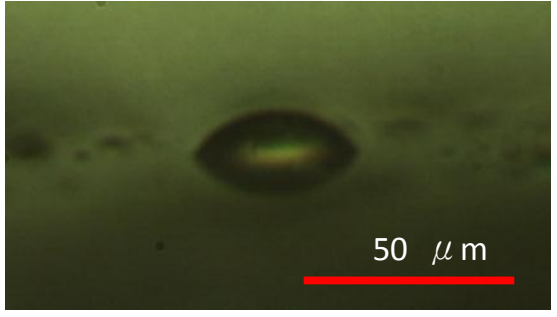

(a)

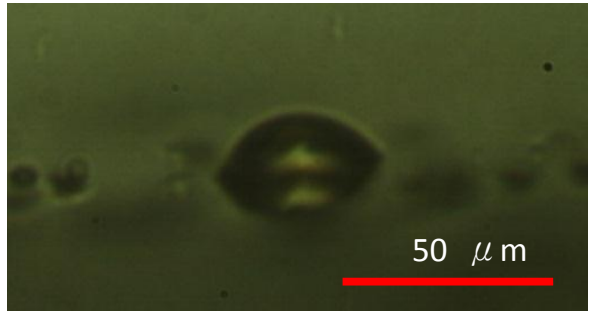

(b)

Figure $4.40 \mu \mathrm{m}$ droplet in $20 \mu \mathrm{g} / \mathrm{ml}$ protein solution after (a) $0 \mathrm{~min}$ and(b) 30 mins.

\section{Results}

The droplet images were captured by CCD camera. As shown in Figure 4, the contact angle of the $40 \mu \mathrm{m}$ droplet in the $20 \mu \mathrm{g} / \mathrm{ml}$ protein solution changed after ten minutes. Figures 5 to 7 show the contact angle change results for the different sized microdroplets in three concentrations of protein solution. The sensitivity of the sensor is seen to vary with the size of themicrodroplet and the concentration of the protein. In a high concentration protein $(0.5 \mathrm{mg} / \mathrm{ml})$, all three microdroplets sizes achieved the final contact angle in fifteen minutes. The largest change of contact angle occurred in the smallest microdroplet, while the smallest change occurred in the largest microdroplet. In addition, for all microdroplet sizes, a reduction in the protein solution concentration slows the reaction time. For the $20 \mu \mathrm{g} / \mathrm{ml}$ and $0.4 \mu \mathrm{g} / \mathrm{ml}$ protein solutions, equilibrium was reached after sixty and one hundred and twenty minutes, respectively. Alternatively, Figure 8 shows the contact change transformed into a curvature change with different concentrations in the same microdroplet size. For the same droplet size, the radius of the curvature increases with the protein concentration. For the same concentration, the curvature change increases with the size of the mircodroplet.

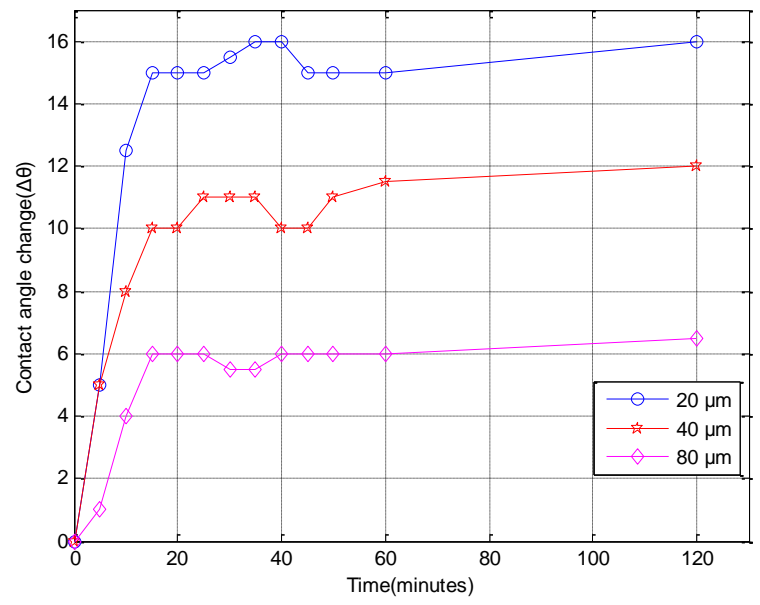

Figure 5 . Contact angle change in $0.5 \mathrm{mg} / \mathrm{ml}$ protein solution.

www.ausmt.org

Copyright (C) 2012 International Journal of Automation and Smart Technology

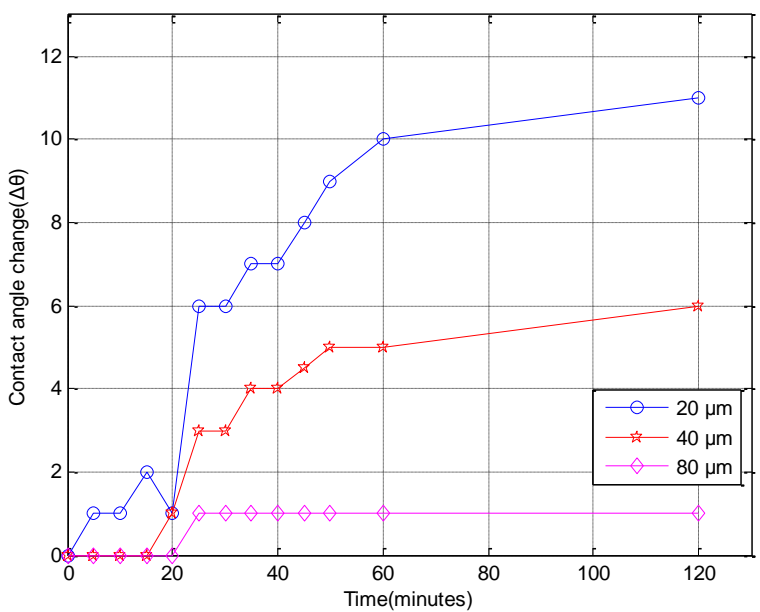

Figure 6. Contact angle change in $20 \mu \mathrm{g} / \mathrm{ml}$ protein solution.

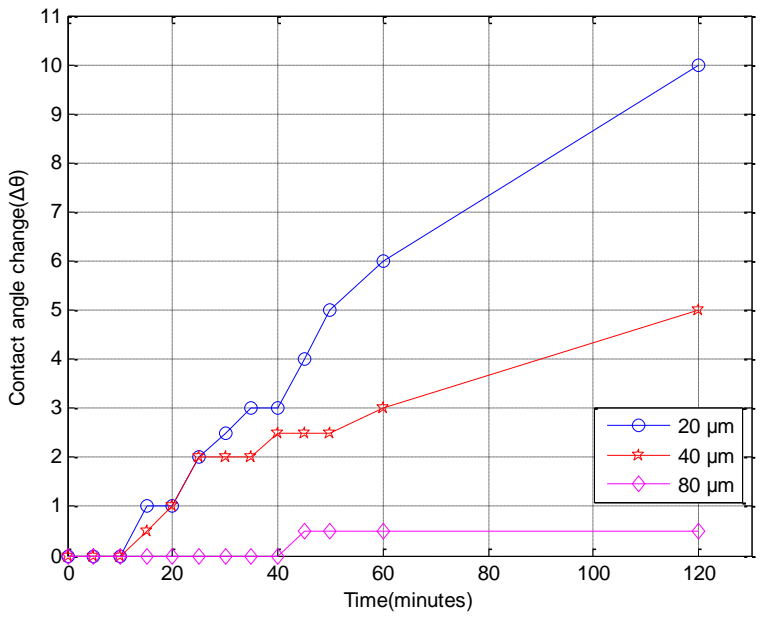

Figure 7. Contact angle change in $0.4 \mu \mathrm{g} / \mathrm{ml}$ protein solution.

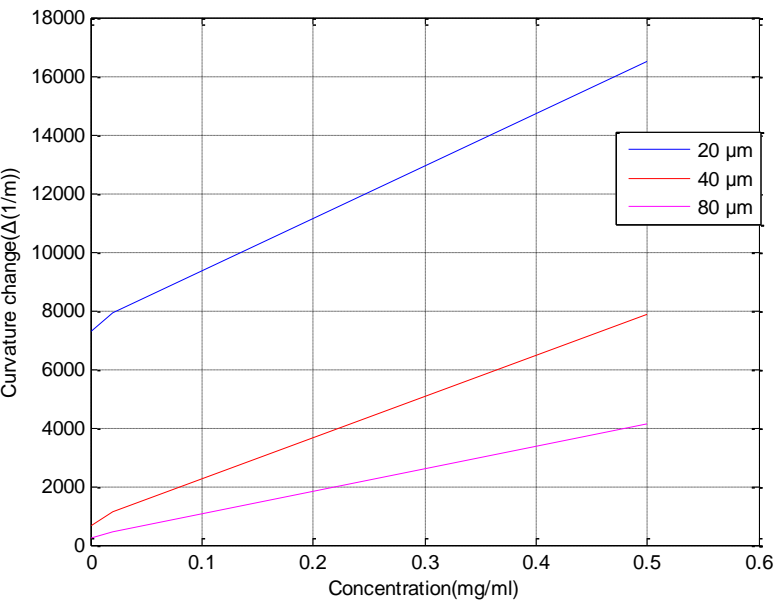

Figure 8. Protein concentration and curvature change. 


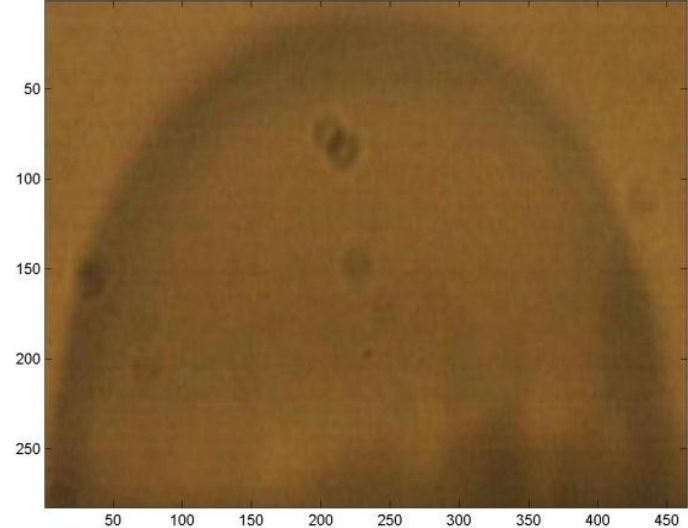

Figure 9. Microdroplet image captured by CCD.

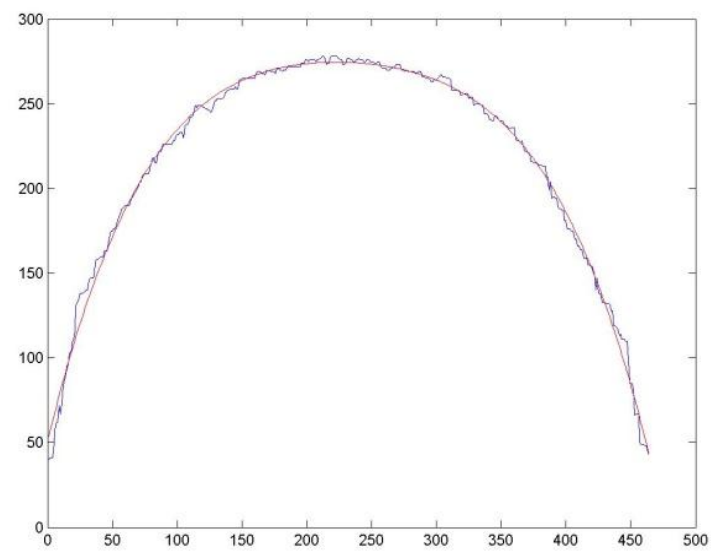

Figure 10. Curve fitting results.

\section{Discussion and Conclusion}

\section{Error estimation}

Suppose the droplet is one part of a circle and the estimated error is +/- one pixel. For the calculated result, the error is $0.64^{\circ}$. Alternatively, MATLAB is used to fit the droplet profile to the CCD image, as shown Figures 9 and 10. The black line is the profile of the microdroplet captured by MATLAB, and the red line is the fitting curve with the polynomial.

\section{Contact angle change}

The contact angle change is shown in Figures 5 to 7. The droplet size is seen to be negatively correlated to the degree of contact angle change. For example, in Figure 5, the respective contact angle changes from $20 \mu \mathrm{m}, 40 \mu \mathrm{m}$, and $80 \mu \mathrm{m}$ are $15^{\circ}, 11^{\circ}, 6^{\circ}$. In addition, the protein concentration is positively correlated with the degree of contact angle change. For the $40 \mu \mathrm{m}$ droplets, the respective change of contact angle in $0.5 \mathrm{mg} / \mathrm{ml}$ and 0.4 $\mu \mathrm{g} / \mathrm{ml}$ was $11^{\circ}$ and $5^{\circ}$. Reaction time is also found to depend on protein concentration, with the $0.4 \mu \mathrm{g} / \mathrm{ml}$ solution taking 120 minutes to reach equilibrium, as opposed to only 15 minutes for the $0.5 \mathrm{mg} / \mathrm{ml}$ solution. In conclusion, the proposed protein sensor can detect a $0.4 \mu \mathrm{g} / \mathrm{ml}$ protein solution in 120 minutes, with the change in contact angle varying with microdroplet size, protein concentration, and reaction time.

\section{References}

[1] F. Scheller and F. Schubert, Biosensors. New York: Elsevier, 1992.

[2] P. N. Prasad, Introduction to biophotonics. New Jersey: Wiley-Interscience, 2003.

[3] G. Veith, "High resolution photoacoustic microscopy on a surface acoustic wave device," Applied Physics Letters, vol. 41, no. 11, pp. 1045-1046, 1982. doi: $10.1063 / 1.93387$

[4] M. R. Bugs and M. L. Cornélio, "A new biophysics approach using photoacoustic spectroscopy to study the DNA-ethidium bromide interaction," European Biophysics Journal, vol. 31, no. 3, pp. 232-240, 2002.

doi: $10.1007 / \mathrm{s} 00249-002-0205-7$

[5] M. Harada, K. Iwamoto, T. Kitamori, and T. Sawada, "Photothermal microscopy with excitation and probe beams coaxial under the microscope and its application to microparticle analysis," Analytical Chemistry, vol. 65, no. 20, pp. 2938-2940, 1993. doi: 10.1021/ac00068a037

[6] K. Matsubara, S. Kawata, and S. Minami, "A compact surface plasmon resonance sensor for measurement of water in process," Applied Spectroscopy, vol. 42, no. 8, pp. 1375-1379, 1988

[7] J. Homola, H. B. Lu, G. G. Nenninger, J. Dostálek, and S. S. Yee, "A novel multichannel surface plasmon resonance biosensor," Sensors and Actuators B: Chemical, vol. 76, no. 1-3, pp. 403-410, 2001. doi: 10.1016/S0925-4005(01)00648-7

[8] A. V. Kabashin and P. I. Nikitin, "Surface plasmon resonance interferometer for bio- and chemical-sensors," Optics Communications, vol. 150, no. 1-6, pp. 5-8, 1998. doi: $10.1016 /$ S0030-4018(97)00726-8

[9] R. D. Harris and J. S. Wilkinson, "Waveguide surface plasmon resonance sensors," Sensors and Actuators B: Chemical, vol. 29, no. 1-3, pp. 261-267, 1995. doi: 10.1016/0925-4005(95)01692-9

[10] P. Dutta, C. A. Tipple, N. V. Lavrik, P. G. Datskos, H. Hofstetter, O. Hofstetter, and M. J. Sepaniak, "Enantioselective sensors based on antibody-mediated nanomechanics," Analytical Chemistry, vol. 75, no. 10, pp. 2342-2348, 2003. doi: $10.1021 / a c 034031 z$ 
[11] C. Y. Tu, T. Kitamori, T. Sawada, H. Kimura, and S. Matsuzawa, "Ultrasensitive heterogeneous immunoassay using photothermal deflection spectroscopy," Analytical Chemistry, vol. 65, no. 24, pp. 3631-3635, 1993. doi: $10.1021 / \mathrm{ac00072a016}$

[12] C. C. Cheng and J. A. Yeh, "Dielectrically actuated liquid lens," Optics Express, vol. 15, no. 12, pp. 7140-7145, 2007. doi: $10.1364 / O E .15 .007140$

[13] C. C. Yang, C. W. G. Tsai, and J. A. Yeh, "Dynamic behavior of liquid microlenses actuated using dielectric force," Journal of Microelectromechanical Systems, vol. 20, no. 5, pp. 1143-1149, 2011. doi: 10.1109/JMEMS.2011.2162493

[14] Y. S. Lu, L. Y. Tsai, K. C. Huang, C. G. Tsai, C. C. Yang, and J. A. Yeh, "Three-dimensional illumination system using dielectric liquid lenses," Optics Express, vol. 19, no. S4, pp. A740-A746, 2011. doi: $10.1364 / O E .19 .00 A 740$

[15] C. C. Cheng, C. A. Chang, and J. A. Yeh, "Variable focus dielectric liquid droplet lens," Optics Express, vol. 14, no. 9, pp. 4101-4106, 2006. doi: 10.1364/OE.14.004101

[16] H. S. Mansur, R. L. Oréfice, W. L. Vasconcelos, Z. P. Lobato, and L. J. C. Machado, "Biomaterial with chemically engineered surface for protein immobilization," Journal of Materials Science: Materials in Medicine, vol. 16, no. 4, pp. 333-340, 2005. doi: $10.1007 /$ s10856-005-0632-y
[17] A. J. Nijdam, M. Ming-Cheng Cheng, D. H. Geho, R. Fedele, P. Herrmann, K. Killian, V. Espina, E. F. Petricoin lii, L. A. Liotta, and M. Ferrari, "Physicochemically modified silicon as a substrate for protein microarrays," Biomaterials, vol. 28, no. 3, pp. 550-558, 2007. doi: 10.1016/i.biomaterials.2006.08.051

[18] D. Kim, H. G. Lee, H. Jung, and S. H. Kang, "Single-protein molecular interactions on polymer-modified glass substrates for nanoarray chip application using dual-color tirfm," BULLETIN-KOREAN CHEMICAL SOCIETY, vol. 28, no. 5, pp. 783-783, 2007

[19] T. Young, "An essay on the cohesion of fluids," Philosophical Transactions of the Royal Society of London, vol. 95, pp. 65-87, 1805. doi: $10.1098 /$ rstl.1805.0005

[20] S. Vafaei and M. Z. Podowski, "Analysis of the relationship between liquid droplet size and contact angle," Advances in Colloid and Interface Science, vol. 113, no. 2-3, pp. 133-146, 2005. doi: $10.1016 /$ j.cis.2005.03.001

[21] D. Duncan, D. Li, J. Gaydos, and A. W. Neumann, "Correlation of line tension and solid-liquid interfacial tension from the measurement of drop size dependence of contact angles," Journal of Colloid and Interface Science, vol. 169, no. 2, pp. 256-261, 1995 doi: $10.1006 /$ jcis.1995.1032 